Article

\title{
Momentum Investment Strategy Using a Hidden Markov Model
}

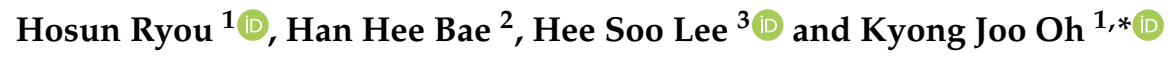 \\ 1 Department of Industrial Engineering, Yonsei University, Seoul 03722, Korea; ryouho@yonsei.ac.kr \\ 2 Department of Investment Information Engineering, Yonsei University, Seoul 03722, Korea; \\ bhh0509@naver.com \\ 3 Department of Business Administration, Sejong University, Seoul 05006, Korea; heesoo@sejong.ac.kr \\ * Correspondence: johanoh@yonsei.ac.kr; Tel.: +82-2-2123-5720
}

Received: 10 August 2020; Accepted: 24 August 2020; Published: 28 August 2020

check for updates

\begin{abstract}
There has been a growing demand for portfolio management using artificial intelligence (AI). To sustain a competitive advantage for portfolio management, stock market investors require a strategic investment decision that can realize better returns. In this study, we propose a momentum investment strategy that employs a hidden Markov model (HMM) to select stocks in the rising state. We construct an HMM momentum portfolio that includes 890 Korean stocks and analyze the performance of the stocks over the period of January 2000 to December 2018. By identifying states of stocks, sectors, and markets through HMM, our strategy buys shares in the rising state and proceeds with rebalancing after the holding period. The HMM momentum portfolio is determined to earn higher returns than traditional momentum portfolios and to achieve the best performance under the conditions of a short holding period (one week) and a short formation period (one month). In addition, our strategy exhibits competitive performance in market and sector index investment compared with market returns. This study implies that the momentum investment strategy using HMM is useful in the Korean stock market. Based on our HMM momentum strategy, future research can be enriched by applying the HMM to developing a new AI momentum strategy that can be utilized for other portfolios containing various types of financial assets on the global market.
\end{abstract}

Keywords: Hidden Markov Model (HMM); momentum investment strategy; financial time series

\section{Introduction}

Predicting the direction of stock markets or examining whether excess returns exist in stock markets is not only the primary concern of market participants but is also a major research topic for academics. An efficient market hypothesis (EMH) was recognized as the core theory of investment until various anomalies in stock markets were found in the 1980s. The EMH states that asset prices fully reflect all available information and that stocks always trade at their fair value, making it impossible for investors to purchase undervalued stocks or sell stocks for inflated prices. On the other hand, the market anomaly proves that due to inefficiency in the process of reflecting information, stock returns follow a certain pattern and provide excess returns. A representative study for identifying expected stock returns is by Fama-French, where a three-factor model is proposed [1,2]. The three factors incorporated in this model are market risk, the outperformance of small versus large companies (SMB, Small Minus Big), and the outperformance of high book/market versus small book/market companies (HML, High Minus Low). Charhart added a momentum factor to the Fama-French three-factor model and showed linear correlations between the momentum factor and stock returns [3]. A recent study by Ayub et al. also incorporated a momentum factor to propose a new six-factor downside beta capital asset pricing model (CAPM) for asset pricing [4]. 
A number of previous studies have focused on momentum investment strategies to sustain competitive advantage for portfolio management. Jegadeesh and Titman demonstrate that a momentum investment strategy of buying a portfolio with good past performance and selling a portfolio with poor past performance can realize significant abnormal returns over a 3- to 12-month holding period [5]. Rouwenhorst analyzed 12 European countries and proved that the momentum investment strategy is effective within a year in developed countries, as well as emerging countries [6]. Griffin et al. analyze emerging Asian markets, as well as the U.S. and European markets, using the momentum investment strategy outlined by Jegadeesh and Titman [7]. The study reports that most countries except Korea, Japan, and Hong Kong have achieved abnormal returns from momentum investment strategies. Moskowitz and Gridblatt show that short-term excess returns from momentum effects could be generated in various portfolios [8]. On the other hand, Aldieri and Vinci explore the relationship between firm size and sustainable innovation in large international firms [9]. They found internal as well as external spillover effects on firms' sizes.

The momentum investment strategy has been a trend-following strategy adopted by many fund managers in the practical field, and these managers have been attempting to improve its performance. Grinold and Kahn use the information ratio (IR) to eliminate the risk of irregularity in the regime transition pattern in the trend-following strategy [10]. These researchers use the formula of $I R=I C \bullet \sqrt{\text { Breadth }}$, where IR measures active management opportunities and squared IR indicates the ability to add value. In this instance, IC (Information Cooperative) represents the management skill, and Breadth represents the number of independent opportunity sets, which is the number of times the skill is used. The trend of investment strategies employed by recent hedge funds is to use a strategy to minimize the risk of regime judgment by increasing the number of independent opportunity sets as much as possible, rather than increasing the IC. Bridgewater Associates, the world's largest hedge fund, is a prime example. Meanwhile, few efforts to increase IC have been made by practitioners and academics. Researchers have recently reported that scientific methodology can be used to improve the accuracy of transition pattern recognition [11,12]. The hidden Markov model (HMM) shows good predictive power for transition pattern recognition [13]. The HMM based on the Markov chain states that one can observe only the results from the hidden states, and the hidden states are only influenced by the present state and have nothing to do with the past state. Therefore, the HMM is useful for time-series pattern recognition that changes over time. Sasikumar and Abdullah describe a detailed idea about the sequence and state prediction of the stock market using HMM and address inferences regarding stock market trends [14]. Hassan and Nath employ the HMM for forecasting stock prices for interrelated markets and compare the results with those from an artificial neural network (ANN) [15]. A recent study by Nguyen determines an optimal number of states for the HMM and predicts monthly closing prices of the S\&P 500 index using the selected HMM [16]. This study shows that the HMM outperforms the buy and hold strategies in predicting and trading stocks. These researchers support the use of the HMM and argue that the HMM offers a new paradigm for stock market forecasting.

There has been a growing demand for portfolio management using artificial intelligence (AI). To sustain a competitive advantage for portfolio management, stock market investors require a strategic investment decision that can realize better returns. Based upon previous finding that the HMM is useful for time-series pattern recognition, this study proposes a momentum investment strategy using the HMM to select stocks in the rising state. We use the HMM to increase the IC in the IR $=I C \bullet \sqrt{\text { Breadth }}$ formula. We construct an HMM momentum portfolio that includes 890 Korean stocks and analyze the performance over the period from January 2000 to December 2018. Identifying states of stocks, sectors, or markets using the HMM, we construct an HMM momentum portfolio by purchasing shares in the rising state and proceeding with rebalancing after the holding period. The HMM momentum portfolio is found to earn higher returns than traditional momentum portfolios and achieves the best performance under certain conditions of the short holding period (one week) and short formation period (one month). In addition, our strategy shows competitive performance in market and sector index investment against market returns. The experimental results in this study imply that the 
momentum investment strategy using HMM is useful in the Korean stock market, and the HMM can be used to develop a new AI momentum strategy that can be utilized for other portfolios containing various types of financial assets on the global market.

A large number of models or techniques for creating an efficient portfolio consisting of various types of instruments have been developed by academics and practitioners. Financial instruments, investment techniques, and investors are critical components in the efficiency of financial markets. An effective investment strategy helps investors to achieve efficient investments as well as an efficient financial market, which are well known to play an important role in sustaining economic growth. Portfolio managers are able to make more efficient strategies by using our HMM momentum investment strategy. It helps to sustain a competitive advantage for portfolio management and contributes to the efficiency of financial markets. In this sense, the HMM momentum investment strategy developed in this paper plays a role in sustaining economic growth.

We organize this paper as follows. Section 2 includes the materials and methods. In this section, we describe the HMM, momentum strategy, and our proposed model. The experimental results and an analysis of the results are presented in Section 3, and Section 4 offers a summary and concluding remarks.

\section{Materials and Methods}

\subsection{Hidden Markov Model (HMM)}

HMM is useful for temporal pattern recognition of time series data and is primarily used for speech recognition, context prediction, protein and DNA structure analysis, and asset price prediction [17-19]. HMM is based on the Markov chain, which is a stochastic model describing a sequence of possible events in which the probability of each event depends only on the state attained in the previous event. The HMM assumes that states are hidden and unobservable. Therefore, this model is a process of inferring states stochastically using observations. In other words, the HMM is a dual stochastic process that models the stochastic process in an unobservable state through another stochastic process of observations. The HMM incorporates two sets of states, that is, hidden states and observation, and it incorporates three probability sets: $\pi$ vector, state transition matrix, and observation probability matrix. The model has two parameters: transition probabilities and emission probabilities. There are several methods of estimating the parameters of the HMM given observations. In the beginning, forward-backward retention and marginal smoothing probabilities were used to estimate the HMM parameters [20]. Later, extensive research using the HMM was conducted after Baum proposed the Baum-Welch algorithm and established a basic theory [21-23]. Then, Viterbi developed an algorithm that is a dynamic planning algorithm to identify the sequence of hidden states [24]. In addition, a method of optimizing the parameters of the Markov model to match the observed signal patterns has been developed [25]. As a result, the HMM has been employed in a wide range of applications, such as the development of systems for advanced speech recognition and human posture recognition [26,27].

In the standard type of HMM, the state space of the hidden variables is discrete, while the observations themselves can be either discrete or continuous. The discrete HMM presents the relationship between the state and variables in a feature emission matrix of emission probabilities, while the continuous HMM describes it using a probability density function. Figure 1 shows the structure of states in the HMM. The variable $\pi$ represents the initial probability of states, and there are a set of observations $\left(O_{n}\right)$ that correspond to a set of hidden states $\left(S_{n}\right)$. The state transition matrix consists of a square matrix that exhibits the probabilities of different states going from one to another, and the observation probability matrix presents the observation probabilities from every state. 


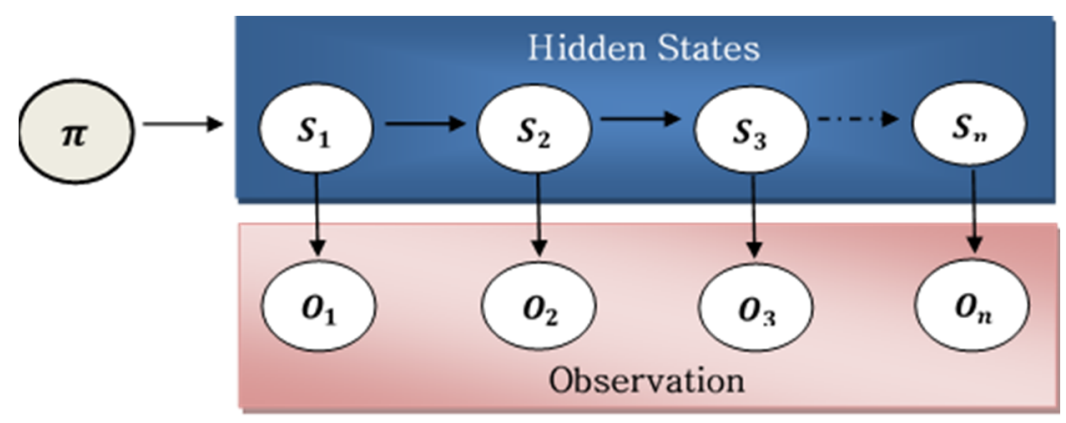

Figure 1. Structure of states in the Hidden Markov Model (HMM).

\subsection{Momentum Strategy}

The momentum strategy is typically implemented by buying assets with past positive returns and selling (shorting) assets with past negative returns under the assumption that past winners tend to continue to yield positive returns, while past losers tend to continue to yield negative returns. There are two types of momentum: relative momentum and absolute momentum. The relative momentum strategy considers relative stock returns, while the absolute momentum strategy considers absolute stock returns. Relative momentum investors buy outperforming assets and sell underperforming assets by comparing assts against one another's past performance. However, absolute momentum investors compare an asset against its own historical performance. These investors buy positive returning assets and sell negative returning assets. The primary difference is that relative momentum makes no distinction about return direction. If all assets are losing value, relative momentum will seek to invest in assets that are going down the least, while absolute momentum will seek to avoid negative returning assets. For example, when all stocks show negative returns, the absolute momentum strategy does not buy any stocks, while the relative momentum strategy buys stocks that are going down the least.

The momentum investment strategy proposed by Jegadeesh and Titman is widely utilized by practitioners and academics [5]. The portfolio formation period (J) and holding period (K) need to be set first to implement the momentum investment strategy. The portfolio formation period $(\mathrm{J})$ is the past return period required to measure the momentum, such as 1,3,6, 9, and 12 months prior to the portfolio construction time. The holding period $(\mathrm{K})$ is the amount of time that the portfolio is held by an investor. For example, a portfolio with $\mathrm{J}=1$ and $\mathrm{K}=3$ includes stocks that recorded positive returns for one month prior to the portfolio construction time, and it is held for the next three months to generate monthly average return.

Since the late 1990s, the momentum strategy has received extensive research attention in the finance discipline. Initial studies revealed that the momentum investment strategy is profitable in the national stock market for several developed countries [6,28]. A momentum effect has also been found in foreign exchange markets [29]. In the following years, stocks in emerging markets have also shown momentum effects [30]. In addition, the momentum effect has been determined to exist during both economic booms and recessions [31]. Later, the momentum effect was found to be significant for corporate bonds and government bonds [32,33].

In all the experiments in this study, we use a long-only absolute momentum strategy to buy only stocks or index with positive returns.

\subsection{Proposed Models}

\subsubsection{HMM Stock Momentum Strategy}

The momentum investment strategy identifies upward momentum assets using their returns over a certain period in the past. In this study, we employ the HMM to identify upward momentum stocks to improve portfolio performance. The HMM is widely employed to describe a given time series, 
and it has recently been applied in the financial field. Stock prices have a trend that is a representative feature of the time series, and the trend changes as the regime shifts. The HMM has been proven to be an excellent model for this time series transition and trend [13]. As mentioned earlier, the effectiveness of the momentum strategy has been proven in many studies $[6,28,30]$. On the other hand, the effectiveness of the momentum strategy in a number of Asian countries, including Korea, is controversial [34]. Therefore, in this study, we employ the HMM momentum investment strategy to examine its usefulness for Korean stock portfolios. We use a continuous HMM with a mixed normal distribution and adopt the momentum investment strategy used by Jegadeesh and Titman [5]. We implement an upward momentum strategy of buying stocks in the rising state using the HMM and evaluate portfolio performance. To this end, we conduct a number of experiments with various ranges of the portfolio formation period $(\mathrm{J})$ and holding period $(\mathrm{K})$. Then, the utility of the upward momentum strategy with HMM is assessed by obtaining the portfolio returns and comparing returns from our portfolios with those from portfolios constructed by the existing momentum strategy.

In the HMM study for stock prediction, it is common to divide the state into three states: ascending, transverse, and falling. In this study, the state is divided into 2, 3, 4, and 5, and the effect of the number of states on stock price prediction is analyzed. As the stock prices are determined to be nonstationary time series, implying that trends and volatility are not constant, we use the series of stock price differences for the trend and the logarithmic stock prices for the volatility to normalize our time series data. In this study, we use the 1-month sliding window method for learning the HMM and depmixS4, which is the R package known to be the most suitable for HMM coding and experiments, to estimate the model [35].

\subsubsection{HMM Sector-Stock Momentum Strategy}

We extend the HMM stock momentum strategy by adding a procedure of identifying upward momentum sectors. The HMM is first used to identify upward momentum sectors and then identify upward moment stocks that belong to the upward momentum sectors. Using industry indices, we first identify upward momentum sectors within 19 industries and then identify upward momentum stocks included in the upward momentum sectors. In other words, we construct a portfolio that buys upward momentum stocks included in upward momentum sectors.

\subsubsection{HMM Index Momentum Strategy}

In this study, we propose an index momentum strategy using the HMM. The states of each sector and overall market are identified by the HMM, and the index momentum portfolios are constructed by the purchasing index in the rising states. We used 20 indices: 19 industry indices and the Korea Composite Stock Price Index (KOSPI). All indices are traded the same way as exchange traded funds (ETFs), and index returns are derived. All experimental models of this study are represented in Figure 2. The upper part of Figure 2, the traditional momentum portfolio, shows the process of constructing a traditional stock long-only momentum portfolio and a traditional sector-stock long-only momentum portfolio. The lower part of Figure 2, the HMM momentum portfolio, shows the process of constructing an HMM stock long-only momentum portfolio and an HMM sector-stock long-only momentum portfolio. As a last step, we compare the performance of the momentum strategy presented by Jegadeesh and Titman [5] with the HMM momentum strategy developed in this study. 


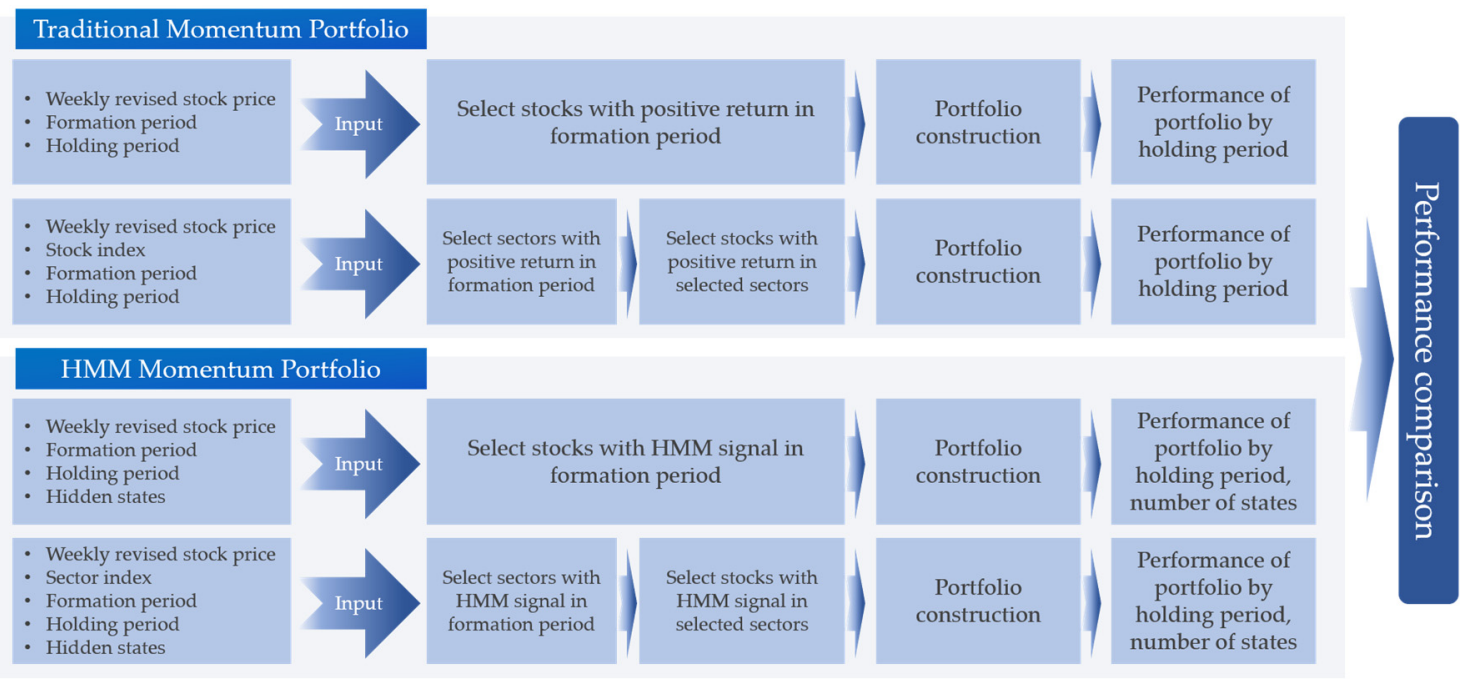

Figure 2. Experimental models for portfolio construction.

\section{Experimental Results}

The experimental part is largely divided into three sections: the stock long-only momentum portfolio, the sector-stock long-only momentum portfolio, and the HMM index long-only momentum portfolio. We use adjusted prices of 960 stocks listed on KOSPI, 19 industry indices, and the KOSPI index from January 2000 to December 2018 provided by Fn-Guide, which is a database of Korean stock markets. We exclude assets with missing data within the formation or holding periods from the portfolio. In all experiments in this study, we use a long-only absolute momentum strategy to construct a traditional momentum portfolio based on the linear model as well as an HMM momentum portfolio based on the nonlinear AI model. Then, the performance of these two portfolios is compared by monthly average returns.

\subsection{Stock Long-Only Momentum Portfolio}

\subsubsection{Traditional Stock Long-Only Momentum Portfolio}

The traditional momentum investment strategy is typically implemented by buying past winners and selling (shorting) past losers under the assumption that past winners tend to continue to yield positive returns, while past losers tend to continue to yield negative returns. We construct a traditional long-only momentum portfolio that includes upward momentum stocks during the formation period and hold it during the holding period [5]. The performance of the portfolio is measured by the monthly average returns of individual stocks included in the portfolio, as described by the following equation:

$$
R_{P, T}=\frac{1}{n} \sum_{i=1}^{n} r_{i, T} \text { where } r_{i, T}=\frac{1}{T} \sum_{t=1}^{T} r_{i, t}
$$

where $R_{P, T}$ denotes the monthly average returns of a portfolio that includes $n$ stocks during $T$ months, $r_{i, T}$ is the monthly average returns of stock $i$ during $T$ months, and $r_{i, t}$ is the monthly returns of stock $i$ in month $t$. The portfolio returns by (1) represents the returns of an equally weighted portfolio of stocks.

Table 1 shows the monthly average return of the traditional stock long-only momentum portfolio constructed across various ranges of formation and holding periods of $1,3,6$, 9, and 12 months. The portfolio includes stocks whose J-month lagged returns are positive. After a portfolio is constructed, it is held for $\mathrm{K}$ months and rebalanced during the experimental period. The portfolio performance is evaluated by monthly average returns, ignoring slippage and trading cost. 
Table 1. Monthly average returns of the traditional stock momentum portfolio.

\begin{tabular}{|c|c|c|c|c|c|c|}
\hline $\mathbf{K}$ & 1 & 3 & 6 & 9 & 12 & Average \\
\hline 1 & 0.75 & 0.73 & 0.79 & 1.07 & 1.13 & 0.89 \\
\hline 3 & 0.69 & 0.79 & 0.83 & 1.15 & 1.13 & 0.92 \\
\hline 6 & 0.98 & 1.06 & 0.92 & 1.12 & 1.02 & 1.02 \\
\hline 9 & 1.11 & 1.13 & 1.36 & 1.12 & 1.04 & 1.15 \\
\hline 12 & 1.28 & 1.40 & 1.24 & 1.17 & 1.12 & 1.24 \\
\hline Average & 0.96 & 1.02 & 1.03 & 1.13 & 1.09 & \\
\hline
\end{tabular}

\subsubsection{HMM Stock Long-Only Momentum Portfolio}

While the traditional momentum investment strategy is to buy only stocks that have shown positive past returns, the HMM momentum investment strategy uses past returns of stocks to determine the state of each stock using HMM and buys only stocks in the rising state. We construct portfolios with formation and holding periods of $1,3,6,9$, and 12 months and conduct the experiment with various numbers of hidden states, including $2,3,4$, and 5 . We use the 1-month sliding window method for learning the HMM. Table 2 shows the monthly average return of the HMM long-only momentum portfolio constructed across various ranges of formation and holding periods of 1,3,6, 9, and 12 months with 2,3,4, and 5 hidden states.

As shown in Table 2, the HMM long-only stock momentum portfolios outperform the traditional long-only momentum portfolios in all cases. Regarding the formation period (J), portfolios constructed by 6-, 9-, and 12-month lagged returns are found to generate higher returns than those constructed by 1 - and 3-month lagged returns. It is also noted that portfolios held for one month exhibit the best performance within most formation periods. On the other hand, the number of states does not affect the portfolio performance. To summarize the results of the experiment, the HMM momentum investment strategy generates higher returns with formation periods of 6,9 and 12 months and a 1-month holding period. The results in Table 2 are illustrated graphically in Figure 3.

As shown in Figure 3, portfolios perform best in the shortest holding period, that is, one month. In other words, the usefulness of HMM increases as the portfolio rebalancing period decreases. Therefore, we conduct an additional experiment with weekly rebalancing using the formation periods and number of states used in Table 2. Table 3 shows the monthly average returns of the HMM long-only momentum portfolio with weekly rebalancing, and the results in Table 3 are illustrated graphically in Figure 4. As shown in Table 3 and Figure 4, weekly rebalancing generates higher returns than monthly rebalancing in all combinations of formation periods and number of states. It should be noted that unlike the results in Table 2, the best performance is achieved when the formation period is one month $(\mathrm{J}=1)$. 
Table 2. Monthly average returns of the HMM stock momentum portfolio.

\begin{tabular}{|c|c|c|c|c|c|c|}
\hline 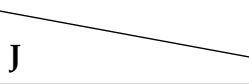 & 1 & 3 & 6 & 9 & 12 & Average \\
\hline \multicolumn{7}{|c|}{ Panel A. 2-Hidden States } \\
\hline 1 & 1.23 & 0.94 & 0.95 & 1.13 & 1.07 & 1.06 \\
\hline 3 & 1.20 & 1.01 & 1.03 & 1.24 & 1.15 & 1.13 \\
\hline 6 & 1.28 & 1.26 & 1.17 & 1.23 & 1.17 & 1.22 \\
\hline 9 & 1.43 & 1.33 & 1.27 & 1.22 & 1.18 & 1.29 \\
\hline 12 & 1.45 & 1.35 & 1.25 & 1.18 & 1.10 & 1.27 \\
\hline Average & 1.32 & 1.18 & 1.13 & 1.2 & 1.13 & \\
\hline \multicolumn{7}{|c|}{ Panel B. 3-Hidden States } \\
\hline 1 & 1.31 & 0.92 & 0.92 & 1.14 & 1.18 & 1.09 \\
\hline 3 & 1.16 & 1.09 & 0.98 & 1.26 & 1.20 & 1.14 \\
\hline 6 & 1.41 & 1.35 & 1.35 & 1.26 & 1.13 & 1.30 \\
\hline 9 & 1.39 & 1.42 & 1.29 & 1.23 & 1.15 & 1.30 \\
\hline 12 & 1.43 & 1.38 & 1.34 & 1.28 & 1.25 & 1.34 \\
\hline Average & 1.34 & 1.23 & 1.18 & 1.23 & 1.18 & \\
\hline \multicolumn{7}{|c|}{ Panel C. 4-Hidden States } \\
\hline 1 & 1.23 & 0.83 & 0.85 & 1.11 & 1.14 & 1.03 \\
\hline 3 & 1.24 & 1.19 & 0.97 & 1.26 & 1.17 & 1.17 \\
\hline 6 & 1.37 & 1.35 & 1.33 & 1.28 & 1.15 & 1.30 \\
\hline 9 & 1.44 & 1.34 & 1.27 & 1.24 & 1.21 & 1.30 \\
\hline 12 & 1.37 & 1.32 & 1.41 & 1.27 & 1.19 & 1.31 \\
\hline Average & 1.33 & 1.21 & 1.17 & 1.23 & 1.17 & \\
\hline \multicolumn{7}{|c|}{ Panel D. 5-Hidden States } \\
\hline 1 & 1.13 & 0.82 & 0.85 & 1.14 & 1.18 & 1.02 \\
\hline 3 & 1.16 & 1.20 & 0.97 & 1.26 & 1.22 & 1.16 \\
\hline 6 & 1.33 & 1.25 & 1.33 & 1.27 & 1.13 & 1.26 \\
\hline 9 & 1.40 & 1.29 & 1.15 & 1.26 & 1.14 & 1.25 \\
\hline 12 & 1.40 & 1.37 & 1.28 & 1.24 & 1.11 & 1.28 \\
\hline Average & 1.28 & 1.19 & 1.12 & 1.23 & 1.16 & \\
\hline
\end{tabular}

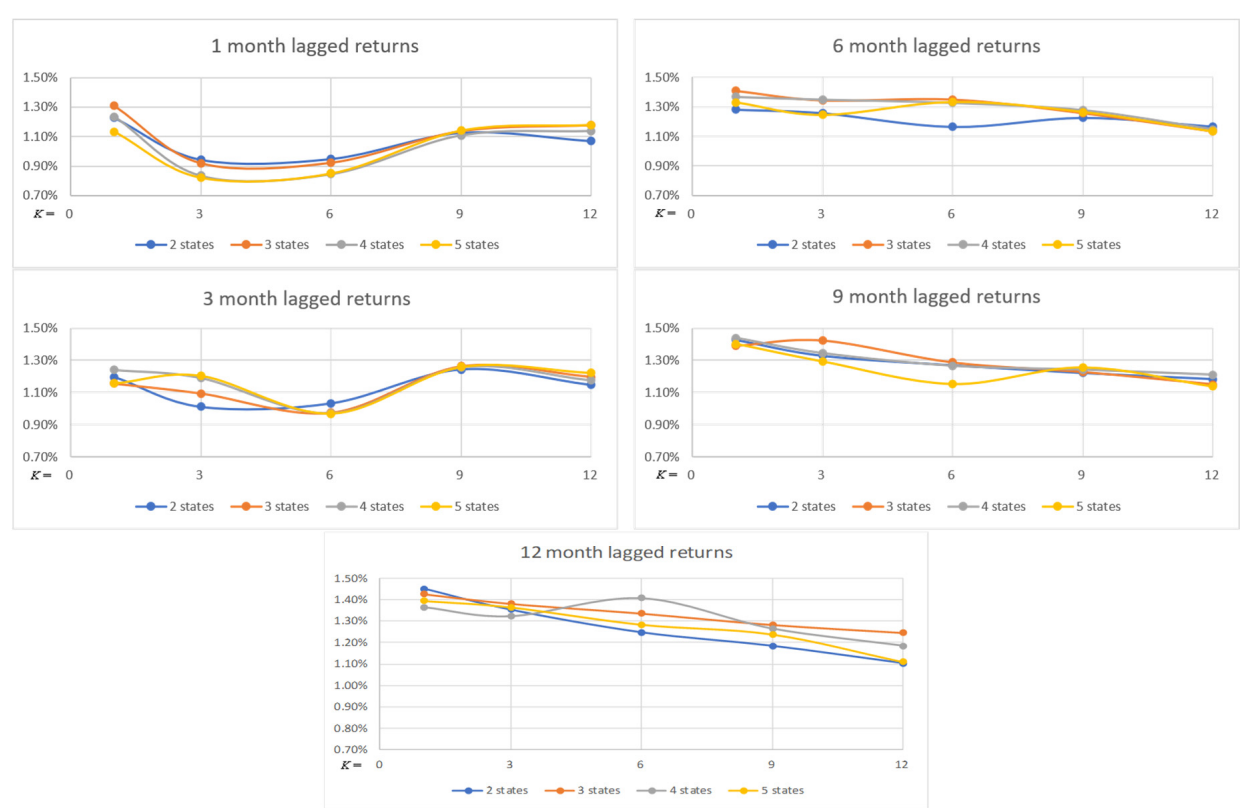

Figure 3. Monthly average return of HMM stock momentum portfolio when $\mathrm{J}=1,3,6,9,12$ months. 
Table 3. Monthly average returns of the HMM stock momentum portfolio with weekly rebalancing.

\begin{tabular}{ccccccc}
\hline $\mathbf{J}$ & \multicolumn{1}{c}{ States } & $\mathbf{2}$ & $\mathbf{3}$ & $\mathbf{4}$ & $\mathbf{5}$ & Average \\
\cline { 1 - 4 } 1 & & & & & & \\
3 & 1.91 & 2.11 & 1.95 & 1.79 & 1.94 \\
6 & 1.57 & 1.57 & 1.65 & 1.58 & 1.59 \\
9 & 1.63 & 1.62 & 1.61 & 1.58 & 1.61 \\
12 & 1.68 & 1.60 & 1.65 & 1.57 & 1.63 \\
Average & 1.65 & 1.67 & 1.58 & 1.58 & 1.62 \\
\hline
\end{tabular}

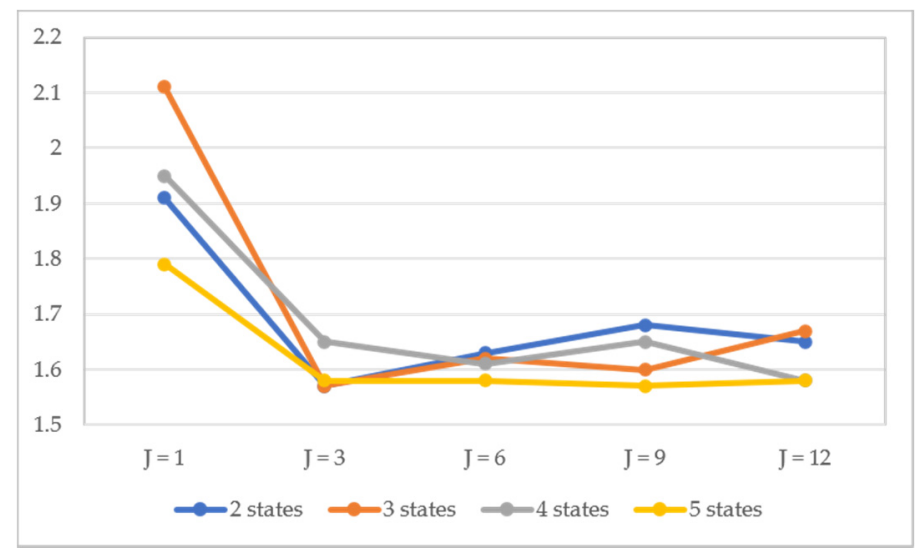

Figure 4. Monthly average returns of the HMM stock momentum portfolio with weekly rebalancing.

\subsection{Sector-Stock Long-Only Momentum Portfolio}

\subsubsection{Traditional Sector-Stock Long-Only Momentum Portfolio}

In this section, portfolios include upward momentum stocks belonging to upward momentum sectors. Using 19 industry indices, we first find sectors of which indices record positive returns and then select stocks that are included in those selected sectors and generate positive returns during the formation period. We construct portfolios across various ranges of formation and holding periods of 1 , $3,6,9$, and 12 months. The results are shown in Table 4 below.

Table 4. Monthly average return of traditional sector-stock momentum portfolio.

\begin{tabular}{|c|c|c|c|c|c|c|}
\hline $\mathbf{K}$ & 1 & 3 & 6 & 9 & 12 & Average \\
\hline 1 & 0.73 & 0.77 & 0.96 & 1.50 & 1.44 & 1.08 \\
\hline 3 & 1.12 & 0.75 & 1.09 & 0.71 & 0.83 & 0.90 \\
\hline 6 & 0.80 & 1.18 & 0.98 & 0.88 & 1.11 & 0.99 \\
\hline 9 & 1.29 & 1.31 & 1.20 & 1.50 & 1.42 & 1.34 \\
\hline 12 & 1.45 & 1.20 & 0.89 & 1.08 & 1.02 & 1.13 \\
\hline Average & 1.08 & 1.04 & 1.02 & 1.13 & 1.16 & \\
\hline
\end{tabular}

\subsubsection{HMM Sector-Stock Long-Only Momentum Portfolio}

In this section, we use HMM to identify upward momentum sectors, as well as upward momentum stocks. We first identify upward momentum sectors among 19 industry indices and then identify upward momentum stocks included in the upward momentum sectors. Similar to the experiment in Section 3.1.2, we construct portfolios with formation and holding periods of 1, 3, 6, 9, and 12 months and perform the experiment with various numbers of hidden states, including 2, 3, 4, and 5 . We use the 1-month sliding window method for learning the HMM. Table 5 shows the monthly average return of 
the HMM sector-stock long-only momentum portfolio. The results presented in Table 5 are illustrated graphically in Figure 5.

Table 5. Monthly average return of HMM sector-stock momentum portfolio.

\begin{tabular}{|c|c|c|c|c|c|c|}
\hline $\mathrm{J}$ & 1 & 3 & 6 & 9 & 12 & Average \\
\hline \multicolumn{7}{|c|}{ Panel A. 2-Hidden States } \\
\hline 1 & 1.31 & 0.76 & 0.78 & 0.91 & 0.96 & 0.94 \\
\hline 3 & 1.35 & 0.81 & 0.90 & 0.88 & 1.04 & 1.00 \\
\hline 6 & 1.28 & 1.22 & 1.25 & 1.24 & 1.14 & 1.23 \\
\hline 9 & 1.63 & 1.40 & 1.52 & 1.23 & 1.13 & 1.38 \\
\hline 12 & 1.56 & 1.30 & 1.30 & 1.13 & 1.21 & 1.30 \\
\hline Average & 1.43 & 1.10 & 1.15 & 1.08 & 1.10 & \\
\hline \multicolumn{7}{|c|}{ Panel B. 3-Hidden States } \\
\hline 1 & 1.37 & 1.13 & 0.97 & 1.12 & 1.03 & 1.12 \\
\hline 3 & 1.35 & 0.82 & 0.65 & 0.83 & 0.89 & 0.91 \\
\hline 6 & 1.67 & 1.13 & 1.11 & 1.29 & 1.14 & 1.27 \\
\hline 9 & 1.51 & 1.47 & 1.05 & 1.56 & 1.12 & 1.34 \\
\hline 12 & 1.39 & 1.31 & 1.14 & 1.21 & 1.19 & 1.25 \\
\hline Average & 1.46 & 1.17 & 0.98 & 1.20 & 1.07 & \\
\hline \multicolumn{7}{|c|}{ Panel C. 4-Hidden States } \\
\hline 1 & 1.29 & 1.26 & 1.36 & 1.13 & 1.13 & 1.23 \\
\hline 3 & 1.47 & 1.17 & 0.78 & 1.22 & 0.98 & 1.12 \\
\hline 6 & 1.50 & 1.23 & 1.16 & 1.11 & 1.25 & 1.25 \\
\hline 9 & 1.52 & 1.30 & 0.85 & 1.14 & 1.12 & 1.19 \\
\hline 12 & 1.52 & 1.01 & 0.94 & 1.07 & 1.22 & 1.15 \\
\hline Average & 1.46 & 1.19 & 1.02 & 1.13 & 1.14 & \\
\hline \multicolumn{7}{|c|}{ Panel D. 5-Hidden States } \\
\hline 1 & 1.46 & 1.08 & 1.15 & 1.26 & 1.09 & 1.21 \\
\hline 3 & 1.56 & 1.01 & 1.05 & 0.67 & 0.90 & 1.04 \\
\hline 6 & 1.52 & 1.36 & 1.18 & 1.21 & 1.50 & 1.35 \\
\hline 9 & 1.63 & 1.46 & 0.80 & 1.08 & 1.20 & 1.23 \\
\hline 12 & 1.76 & 1.22 & 1.13 & 1.41 & 1.02 & 1.31 \\
\hline Average & 1.59 & 1.23 & 1.06 & 1.13 & 1.14 & \\
\hline
\end{tabular}




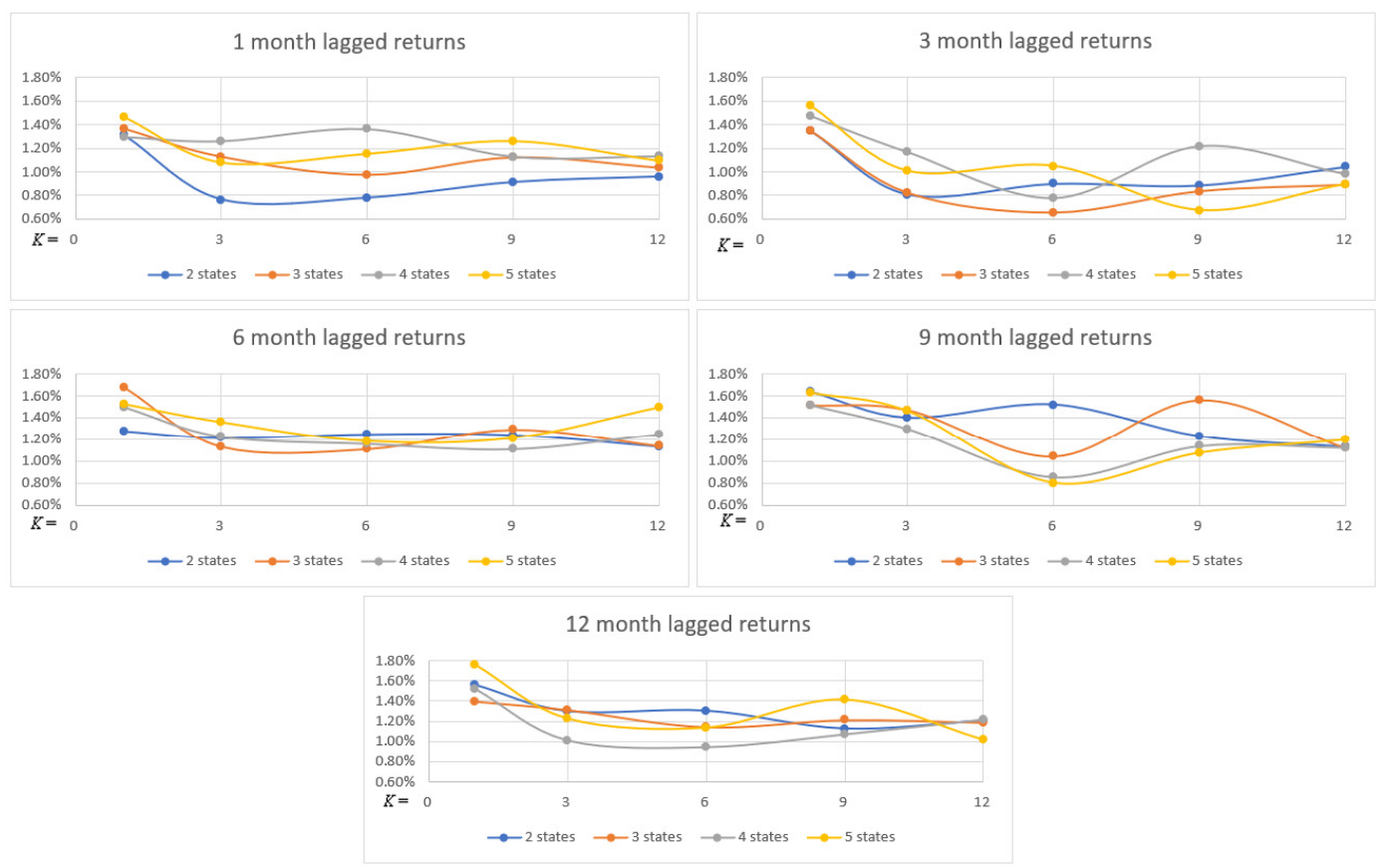

Figure 5. Monthly average returns of the HMM sector-stock momentum portfolio when $\mathrm{J}=1,3,6,9,12$.

As shown in Table 5 and Figure 5, the HMM sector-stock long-only momentum portfolios outperform the traditional long-only momentum portfolios in all combinations of formation and holding periods. Similar to the results of the HMM stock long-only momentum portfolio, portfolios constructed by 6-, 9-, and 12-month formation periods are observed to generate higher returns than those constructed by the 1- and 3-month formation periods. It is also noted that portfolios with a one-month holding period achieve the best performance within most formation periods. Similar to the HMM stock long-only momentum portfolio, the shorter the holding period, the better the performance.

As such, we conduct an additional experiment with weekly rebalancing across the combination of the formation periods and number of states. Table 6 shows the monthly average returns of the HMM sector-stock long-only momentum portfolio with weekly rebalancing, and the results in Table 6 are illustrated graphically in Figure 6. As shown in Table 6 and Figure 6, weekly rebalancing generates higher returns than monthly rebalancing in all combinations of the formation period and number of states. It should be noted that unlike the results presented in Table 5, the best performance is achieved when the formation period is one month $(\mathrm{J}=1)$.

Table 6. Monthly average returns of the HMM sector-stock momentum portfolio with weekly rebalancing.

\begin{tabular}{ccccccc}
\hline $\mathbf{J}$ & \multicolumn{1}{c}{ States } & $\mathbf{2}$ & $\mathbf{3}$ & $\mathbf{4}$ & $\mathbf{5}$ & Average \\
\cline { 1 - 5 } 1 & & & & & & \\
3 & 1.93 & 2.09 & 2.26 & 1.97 & 2.06 \\
6 & 1.71 & 1.62 & 1.98 & 1.77 & 1.77 \\
9 & 1.76 & 1.82 & 1.89 & 1.87 & 1.84 \\
12 & 1.82 & 1.74 & 1.94 & 1.90 & 1.85 \\
Average & 1.70 & 1.56 & 1.64 & 1.91 & 1.70 \\
\hline
\end{tabular}




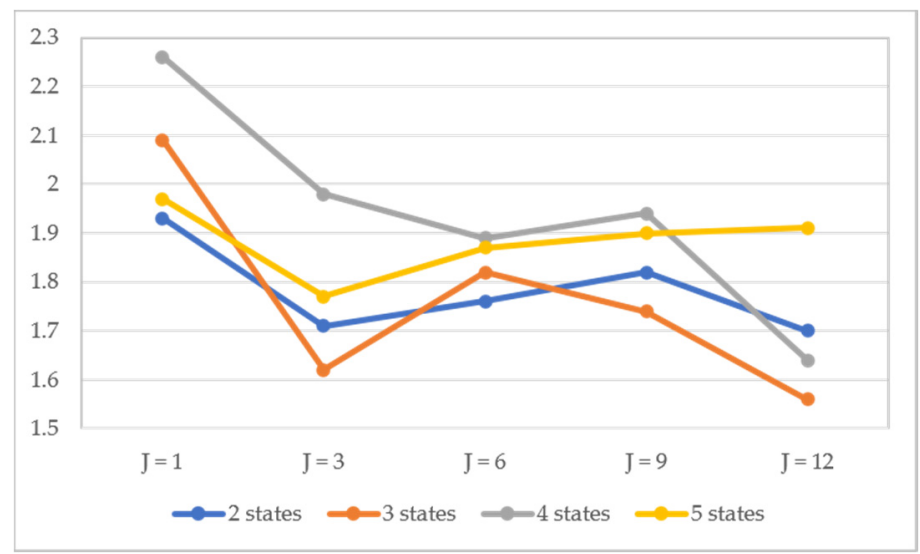

Figure 6. Monthly return of HMM-based sector-stock weekly momentum portfolio.

\subsection{HMM Index Long-Only Momentum Portfolio}

In this section, we use 20 indices, including 19 industry indices and the KOSPI index, to construct the HMM index long-only momentum portfolio. Given the state of each index determined by HMM, we purchase the index only when it is in the rising state, and we rebalance the portfolio every week. The experiment is conducted with a 1-week holding period and a 1-month formation period across 2, 3, 4 , and 5 hidden states. In addition, we employ the buy and hold strategy with indices and compare the performance of the HMM index momentum strategy with those of the buy and hold strategy. We also calculate the ratio of the period during which the portfolio takes a long position to the experimental period, which is denoted by the ratio of the long position period (RLP). Table 7 shows the monthly returns of the HMM index momentum portfolio by 19 sectors and the overall market. The results in Table 7 are illustrated graphically in Figure 7. As shown in Table 7 and Figure 7, monthly returns from the HMM index long-only momentum strategy are observed to be significantly higher than those obtained with the buy and hold strategy for all indices. These results are consistent with those reported by Nguyen [16]. 
Table 7. Monthly returns of HMM index momentum portfolio of 19 sectors and the overall market.

\begin{tabular}{|c|c|c|c|c|c|c|c|}
\hline \multirow{2}{*}{ Index } & \multirow{2}{*}{ Performance } & \multirow{2}{*}{$\begin{array}{l}\text { Buy and } \\
\text { Hold }\end{array}$} & \multicolumn{5}{|c|}{ HMM Index Momentum Strategy } \\
\hline & & & 2 States & 3 States & 4 States & 5 States & Average \\
\hline \multirow{2}{*}{ KOSPI } & RLP (\%) & 100 & 72.53 & 50.81 & 59.67 & 58.07 & 60.27 \\
\hline & Returns & 0.36 & 0.92 & 1.01 & 0.82 & 0.85 & 0.90 \\
\hline \multirow{2}{*}{ Food and Beverage } & RLP (\%) & 100 & 57.40 & 65.34 & 53.50 & 52.03 & 57.07 \\
\hline & Returns & 0.53 & 1.22 & 1.22 & 1.19 & 0.95 & 1.15 \\
\hline \multirow{2}{*}{ Textile and Apparel } & RLP (\%) & 100 & 80.32 & 35.34 & 42.97 & 41.96 & 50.15 \\
\hline & Returns & -0.12 & 0.73 & 1.35 & 1.19 & 0.94 & 1.05 \\
\hline \multirow{2}{*}{ Paper and Wood } & RLP (\%) & 100 & 60.81 & 58.01 & 56.21 & 56.19 & 57.81 \\
\hline & Returns & -0.02 & 1.16 & 1.10 & 1.19 & 1.33 & 1.20 \\
\hline \multirow{2}{*}{ Industrial Materials } & RLP (\%) & 100 & 63.94 & 74.24 & 53.67 & 51.02 & 60.72 \\
\hline & Returns & 0.79 & 1.35 & 1.32 & 1.02 & 1.14 & 1.21 \\
\hline \multirow{2}{*}{$\begin{array}{l}\text { Pharmaceuticals and } \\
\text { Biotechnology }\end{array}$} & RLP (\%) & 100 & 75.76 & 63.49 & 73.83 & 70.37 & 70.86 \\
\hline & Returns & 1.08 & 1.11 & 1.40 & 1.23 & 1.14 & 1.22 \\
\hline \multirow{2}{*}{ Nonferrous Metals } & RLP (\%) & 100 & 54.65 & 71.20 & 52.55 & 57.23 & 58.91 \\
\hline & Returns & 0.55 & 1.45 & 1.47 & 1.32 & 1.27 & 1.38 \\
\hline \multirow{2}{*}{ Steel and Metal } & RLP (\%) & 100 & 53.45 & 50.20 & 52.44 & 50.21 & 51.58 \\
\hline & Returns & 0.57 & 1.53 & 1.22 & 0.97 & 0.96 & 1.17 \\
\hline \multirow{2}{*}{ Machine } & RLP (\%) & 100 & 68.69 & 65.21 & 56.81 & 54.15 & 61.22 \\
\hline & Returns & 0.3 & 1.41 & 1.11 & 1.33 & 1.20 & 1.26 \\
\hline \multirow{2}{*}{$\begin{array}{l}\text { Electronic } \\
\text { Components }\end{array}$} & $\operatorname{RLP}(\%)$ & 100 & 83.23 & 44.62 & 61.10 & 51.18 & 60.03 \\
\hline & Returns & 0.62 & 0.92 & 1.18 & 1.06 & 0.90 & 1.01 \\
\hline \multirow{2}{*}{ Medical Precision } & RLP (\%) & 100 & 63.39 & 60.95 & 44.09 & 63.75 & 58.05 \\
\hline & Returns & 0.42 & 2.60 & 2.24 & 2.13 & 2.16 & 2.28 \\
\hline \multirow{2}{*}{$\begin{array}{c}\text { Transportation and } \\
\text { Equipment }\end{array}$} & RLP (\%) & 100 & 65.35 & 73.83 & 63.03 & 63.82 & 66.51 \\
\hline & Returns & 0.72 & 1.62 & 1.37 & 1.44 & 1.53 & 1.49 \\
\hline \multirow{2}{*}{ Retail and Trading } & RLP (\%) & 100 & 72.53 & 53.14 & 50.51 & 45.12 & 55.33 \\
\hline & Returns & 0.14 & 0.86 & 1.07 & 0.77 & 0.88 & 0.90 \\
\hline \multirow{2}{*}{ Utilities } & RLP (\%) & 100 & 63.94 & 68.46 & 61.10 & 55.37 & 62.22 \\
\hline & Returns & 0.03 & 0.61 & 0.62 & 0.37 & 0.36 & 0.49 \\
\hline \multirow{2}{*}{ Construction } & RLP (\%) & 100 & 68.38 & 39.45 & 44.70 & 58.90 & 52.86 \\
\hline & Returns & 0.08 & 1.10 & 0.74 & 1.06 & 0.90 & 0.95 \\
\hline \multirow{2}{*}{$\begin{array}{c}\text { Transportation and } \\
\text { Logistics }\end{array}$} & RLP (\%) & 100 & 71.81 & 48.68 & 36.15 & 50.98 & 51.91 \\
\hline & Returns & 0.32 & 0.99 & 0.81 & 1.05 & 1.02 & 0.97 \\
\hline \multirow{2}{*}{ Telecom Services } & RLP (\%) & 100 & 53.94 & 52.85 & 49.90 & 42.77 & 49.87 \\
\hline & Returns & -0.32 & -0.11 & 0.40 & 0.11 & -0.26 & 0.04 \\
\hline \multirow{2}{*}{ Bank } & RLP (\%) & 100 & 75.86 & 69.17 & 66.60 & 48.30 & 64.98 \\
\hline & Returns & 0.25 & 0.55 & 0.76 & 0.35 & 0.48 & 0.54 \\
\hline \multirow{2}{*}{ Securities } & RLP (\%) & 100 & 46.57 & 65.21 & 42.78 & 46.95 & 50.38 \\
\hline & Returns & -0.11 & 1.03 & 0.80 & 0.95 & 0.83 & 0.90 \\
\hline \multirow{2}{*}{ Insurance } & RLP (\%) & 100 & 76.17 & 61.87 & 44.70 & 51.23 & 58.49 \\
\hline & Returns & 0.79 & 1.13 & 0.89 & 0.74 & 0.88 & 0.91 \\
\hline
\end{tabular}




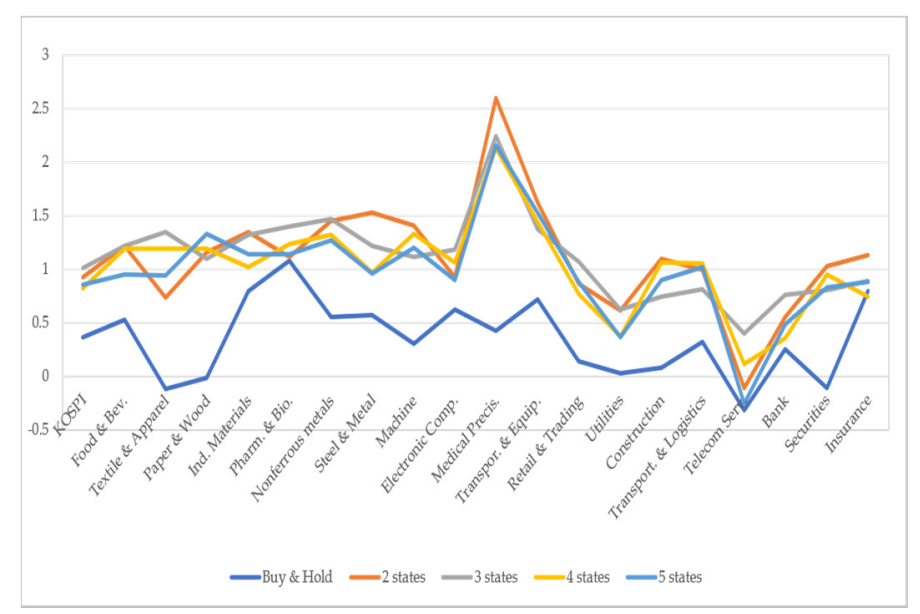

Figure 7. Monthly returns of HMM Index momentum portfolio of 19 sectors and the overall market.

\section{Summary and Conclusions}

This study proposes using HMM in the momentum investment strategy and compares the performance of the HMM momentum portfolio with those of traditional momentum portfolios to demonstrate the usefulness of HMM for the momentum investment strategy. The results of the empirical analysis of this study can be summarized as follows.

First, the HMM stock momentum portfolio (Section 3.1) and HMM sector-stock momentum portfolio (Section 3.2) outperform the corresponding traditional momentum portfolio in all combinations of formation and holding periods.

Second, the results for the HMM stock momentum portfolio and HMM sector-stock momentum portfolio show similar characteristics: the portfolios constructed by 6-, 9-, and 12-month formation periods generate higher returns than those constructed by 1- and 3-month formation periods. It is also observed that portfolios with a 1-month holding period achieve the best performance within most formation periods.

Third, the HMM stock momentum portfolio and HMM sector-stock momentum portfolio with weekly rebalancing improve their performance and generate their best returns with a 1-month formation period.

Fourth, the HMM index momentum investment strategy significantly outperforms the buy and hold strategy for all indices.

In summary, the HMM improves the performance of the momentum strategy for stock portfolios, sector-stock portfolios, industry index portfolios, and KOSPI index portfolios over the period from January 2000 to December 2018. In addition, our experimental results suggest using a 1-month formation period and a 1-week holding period for the HMM momentum investment strategy.

A large number of models or techniques for creating an efficient portfolio consisting of various types of instruments have been developed by academics and practitioners. An effective investment strategy helps investors to achieve efficient investments as well as an efficient financial market, which is well known to play an important role in sustaining economic growth. To sustain a competitive advantage for portfolio management, stock market investors require a strategic investment decision that can maximize returns or minimize losses. The HMM momentum investment strategy can be used by portfolio managers for more efficient portfolios, and it contributes to the efficiency of financial markets. In this sense, the HMM momentum investment strategy developed in this paper plays a role in sustaining economic growth.

While the traditional momentum strategy theorized by Jegadeesh and Titman [4] has been widely used in many studies, the effectiveness of the momentum strategy in the Korean stock market has not been determined. This study indicates that the momentum investment strategy using HMM is useful in the Korean stock market. However, this study has possible limitations. For instance, the 
experimental results are limited to the long-only momentum portfolio of Korean market assets. Based on our HMM momentum strategy, future research can be enriched by applying the HMM to the long-short momentum strategy or developing a new AI momentum strategy that can be utilized for other portfolios containing various types of financial assets on the global market.

Author Contributions: Project administrator, K.J.O.; Programming, formal analysis, H.R.; Proposing methodology, data curation, H.H.B.; Writing, reviewing and editing, H.S.L. All authors have read and agreed to the published version of the manuscript.

Funding: This research received no external funding.

Conflicts of Interest: The authors declare that they have no conflicts of interest.

\section{References}

1. Fama, E.F.; French, K.R. The cross-section of expected stock returns. J. Financ. 1992, 47, 427-465. [CrossRef]

2. Fama, E.F.; French, K.R. Common risk factors in the returns on stocks and bonds. J. Financ. 1993, 33, 3-56. [CrossRef]

3. Carhart, M. On persistence in mutual fund performance. J. Financ. 1997, 52, 57-82. [CrossRef]

4. Ayub, U.; Kausar, S.; Noreen, U.; Zakaria, M.; Jadoon, I.A. Downside risk-based six-factor capital asset pricing model (CAPM): A new paradigm in asset pricing. Sustainability 2020, 12, 6756. [CrossRef]

5. Jegadeesh, N.; Titman, S. Returns to buying winners and selling losers: Implications for stock market efficiency. J. Financ. 1993, 48, 65-91. [CrossRef]

6. Rouwenhorst, K.G. International momentum strategies. J. Financ. 1998, 53, 267-284. [CrossRef]

7. Griffin, J.M.; Ji, X.; Martin, S. Global Momentum Strategies. J. Portf. Manag. 2005, 31, 23-39. [CrossRef]

8. Moskowitz, T.; Grinblatt, M. Do industries explain momentum? J. Financ. 1999, 54, 249-1290. [CrossRef]

9. Aldieri, L.; Vinci, C.P. Firm size and sustainable innovation: A theoretical and empirical analysis. Sustainability 2019, 11, 2775. [CrossRef]

10. Grinold, R.C.; Kahn, R.N. Active Portfolio Management: A Quantitative Approach for Providing Superior Returns and Controlling Risk, 2nd ed.; McGraw-Hill Professional: New York, NY, USA, 2000.

11. Kim, J.; Shin, S.; Lee, H.S.; Oh, K.J. A machine learning portfolio allocation system for IPOs in Korean markets using GA-rough set theory. Sustainability 2019, 11, 6803. [CrossRef]

12. Antonio, M.S.; Francisco, M.A.; Alicia, T.; Jose, L.J.; Cristina, R.E. Pattern recognition to forecast seismic time series. Expert Syst. Appl. 2010, 37, 8333-8342.

13. Hassan, M.R.; Ramamohanarao, K.; Kamruzzaman, J.; Rahman, M.; Hossain, M.M. A HMM-based adaptive fuzzy inference system for stock market forecasting. Neurocomputing 2013, 104, 10-25. [CrossRef]

14. Sasikumar, R.; Abdullah, A.S. Forecasting the stock market values using hidden Markov model. Int. J. Bus. Anal. Int. 2016, 4, 17-21. [CrossRef]

15. Hassan, R.; Nath, B. Stock market forecasting using hidden Markov model: A new approach. In Proceedings of the 5th International Conference on Intelligent Systems Design and Applications (ISDA'05), Warsaw, Poland, 8-10 September 2005; pp. 192-196.

16. Nguyen, N. Hidden Markov model for stock trading. Int. J. Financ. Stud. 2018, 6, 36. [CrossRef]

17. Dimitri, P.; Mathew, M.D.; Ronan, C. End-to-end acoustic modeling using convolutional neural networks for HMM-based automatic speech recognition. Speech Commun. 2019, 108, 15-32.

18. Ahmad, F.; Rahman, M. HMM as an inference technique for context awareness. Procedia Comput. Sci. 2015, 59, 454-458.

19. Paresh, D.; Rogemar, M.; Anton, T. Filtering and forecasting commodity futures prices under an HMM framework. Energy Econ. 2013, 40, 1001-1013.

20. Stratonovich, R.L. Conditional Markov processes. Theory Probab. Appl. 1960, 5, 156-178. [CrossRef]

21. Baum, L.E.; Petrie, T. Statistical inference for probabilistic functions of finite state Markov chains. Ann. Math. Stat. 1966, 37, 1554-1563. [CrossRef]

22. Baum, L.E.; Petrie, T.; Soules, G.; Weiss, N. A maximization technique occurring in the statistical analysis of probabilistic functions of Markov chains. Ann. Math. Stat. 1970, 41, 164-171. [CrossRef]

23. Baum, L.E. An inequality and associated maximization technique in statistical estimation for probabilistic functions of Markov chains. Inequalities 1972, 3, 1-8. 
24. Viterbi, A.J. Error bounds for convolutional codes and an asymptotically optimum decoding algorithm. IEEE T. Inf. Theory 1967, 13, 260-269. [CrossRef]

25. Rabiner, L.R.; Juang, B.H. An Introduction to hidden Markov models. IEEE ASSP Mag. 1986, 3, 4-16. [CrossRef]

26. Rabiner, L.R. A tutorial on hidden Markov models and selected applications in speech recognition. Proc. IEEE 1989, 77, 257-286. [CrossRef]

27. Cai, X.; Gao, Y.; Li, M.; Song, W. Infrared human posture recognition method for monitoring in smart homes based on hidden markov model. Sustainability 2016, 8, 892. [CrossRef]

28. Asness, C.S.; John, M.L.; Ross, L.S. Parallels between the cross-sectional predictability of stock and country returns. J. Portf. Manag. 1997, 23, 79-87. [CrossRef]

29. Lebaron, B. Technical trading rule profitability and foreign exchange intervention. J. Int. Econ. 1999, 49, 125-143. [CrossRef]

30. Rouwenhorst, K.G. Local return factors and turnover in emerging stock markets. J. Financ. 1999, 54, 1439-1464. [CrossRef]

31. Griffin, J.; Ji, X.; Martin, J. Momentum investing and business cycle risk: Evidence from pole to pole. J. Financ. 2003, 58, 2515-2547. [CrossRef]

32. Jostova, G.; Nikolova, S.; Philipov, A.; Stahel, C.W. Momentum in corporate bond returns. Rev. Financ. Stud. 2012, 26, 1649-1693. [CrossRef]

33. Luu, B.V.; Yu, P. Momentum in government-bond markets. J. Fixed Income 2012, 22, 72-79. [CrossRef]

34. Kim, D.H.; Seo, H.J. Empirical study on the performance of style momentum strategies in the Korean stock market. Korean J. Bus. Adm. 2008, 21, 1945-1975.

35. Visser, I.; Speekenbrink, M. depmixS4: An R package for hidden Markov models. J. Stat. Softw. 2010, 36, 1-21. [CrossRef]

(C) 2020 by the authors. Licensee MDPI, Basel, Switzerland. This article is an open access article distributed under the terms and conditions of the Creative Commons Attribution (CC BY) license (http://creativecommons.org/licenses/by/4.0/). 